\title{
Article
}

\section{Measurement of magnetic exchange in asymmetric lanthanide dimetallics: towards a transferable theoretical framework}

Marcus J Giansiracusa, Eufemio Moreno-Pineda, Riaz Hussain, Raphael Marx, María Martínez

Prada, Petr Neugebauer, Susan Al-Badran, David Collison, Floriana Tuna, Joris van Slageren, Stefano Carretta, Tatiana Guidi, Eric J.L. Mclnnes, Richard E. P. Winpenny, and Nicholas F. Chilton

J. Am. Chem. Soc., Just Accepted Manuscript • DOI: 10.1021/jacs.7b10714 • Publication Date (Web): 26 Jan 2018

Downloaded from http://pubs.acs.org on January 27, 2018

\section{Just Accepted}

"Just Accepted" manuscripts have been peer-reviewed and accepted for publication. They are posted online prior to technical editing, formatting for publication and author proofing. The American Chemical Society provides "Just Accepted" as a free service to the research community to expedite the dissemination of scientific material as soon as possible after acceptance. "Just Accepted" manuscripts appear in full in PDF format accompanied by an HTML abstract. "Just Accepted" manuscripts have been fully peer reviewed, but should not be considered the official version of record. They are accessible to all readers and citable by the Digital Object Identifier (DOI@). "Just Accepted" is an optional service offered to authors. Therefore, the "Just Accepted" Web site may not include all articles that will be published in the journal. After a manuscript is technically edited and formatted, it will be removed from the "Just Accepted" Web site and published as an ASAP article. Note that technical editing may introduce minor changes to the manuscript text and/or graphics which could affect content, and all legal disclaimers and ethical guidelines that apply to the journal pertain. ACS cannot be held responsible for errors or consequences arising from the use of information contained in these "Just Accepted" manuscripts. 


\section{Introduction}

Given the recent interest in the use of lanthanide (Ln) ions for quantum information processing $(\mathrm{QIP})^{1-3}$ and in single molecule magnets (SMMs), ${ }^{4-9}$ it is important to understand the nature of magnetic interactions involving these elements. Intramolecular magnetic interactions, irrespective of their strength, can significantly alter the magnetic properties of a molecule by providing alternate electronic relaxation pathways via (i) intermediate states, (ii) mixing of low lying states and (iii) increasing quantum tunneling of the magnetization (QTM) in SMMs. Alternatively, the lifting of ground state degeneracies by exchange interactions can also result in a shift of resonant QTM relaxation steps away from zero-field, known as exchange bias, thus increasing zero-field magnetic remenance. ${ }^{10,11}$ While for QIP, magnetic interactions between $\mathrm{Ln}$ ions has been proposed as a crucial building block for multi-qubit gates. ${ }^{1}$

Excluding some examples of strong magnetic exchange mediated via radical species, ${ }^{12-14}$ superexchange interactions are usually very weak for $\mathrm{Ln}$ ions as a result of the contracted $4 \mathrm{f}$ orbitals. As the magnetic moments of $\mathrm{Ln}$ ions are large, significant magnetic dipole interactions are also common, and possibly of comparable magnitude to superexchange interactions, both being highly

anisotropic owing to the presence of first-order orbital angular momentum. To exploit the potential of Ln-Ln interactions in QIP or SMM prototypes, we must demonstrate chemical control of such interactions; however, this is unlikely until we understand their origin. As-yet, there is no transferrable microscopic Hamiltonian for modelling Ln-Ln magnetic interactions, with recent work suggesting a case-specific formalism may be required. ${ }^{15-17}$ In order to develop a capable theoretical framework and understand the origins of these interactions, there must be sufficient experimental evidence with which to benchmark proposed models.

We have been undertaking a study on the magnetic interactions within simple $\mathrm{Ln}$ dimetallics to define a series of detailed benchmark measurements on which a transferrable theoretical framework can be built. Our approach centers on the use of electron paramagnetic resonance (EPR) spectroscopy to probe the lowest-lying exchange states directly, and we have recently employed this method to measure the magnetic interaction between two Dy(III) ions in the asymmetric dimetallic compound $\left[\mathrm{hqH}_{2}\right]\left[\mathrm{Dy}_{2}(\mathrm{hq})_{4}\left(\mathrm{NO}_{3}\right)_{3}\right] \cdot \mathrm{MeOH}(\mathrm{hq}=8$-hydroxyquinoline, Figure 1). ${ }^{18}$ Here, we extend our study of the $\left[\mathrm{hqH}_{2}\right]\left[\mathrm{Ln}_{2}(\mathrm{hq})_{4}\left(\mathrm{NO}_{3}\right)_{3}\right] \cdot \mathrm{MeOH}$ (herein " $\mathrm{Ln}_{2}$ ") family to the Kramers ions $\operatorname{Er}(\mathrm{III})$ and $\mathrm{Yb}(\mathrm{III})$, which have far more detail in their EPR spectra than for $\mathrm{Dy}_{2}$. We employ inelastic neutron 
scattering (INS), EPR and far-IR (FIR) spectroscopies, magnetometry and complete active space self-consistent field spin-orbit (CASSCF-SO) calculations, to obtain a comprehensive picture of the magnetic states and accurately quantify the anisotropic magnetic exchange between the Ln(III) ions.

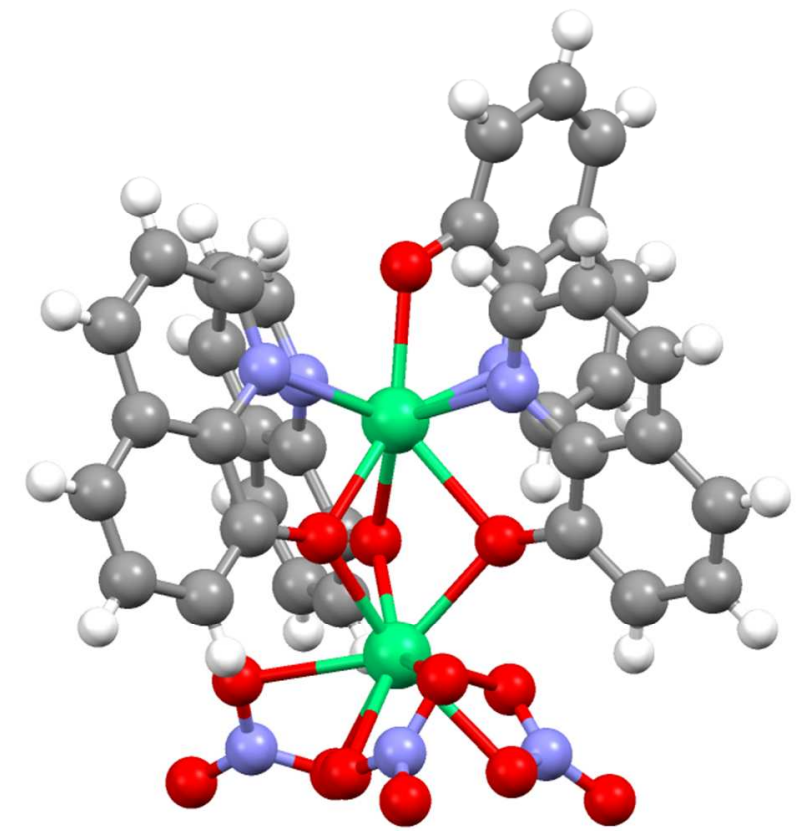

Figure 1. Crystal structure of $\left[\mathrm{Ln}_{2}(\mathrm{hq})_{4}\left(\mathrm{NO}_{3}\right)_{3}\right]^{-}$showing the two different coordination pockets. Upper metal site is the "hq pocket", lower metal site is the " $\mathrm{NO}_{3}$ pocket". Scheme: Ln: green, $\mathrm{O}$ : red, $\mathrm{N}$ : blue, $\mathrm{C}$ : grey and $\mathrm{H}$ : white.

We are not the first to employ spectroscopic methods such as INS and EPR to probe magnetic exchange; for example, INS has often been used to investigate Ln crystal field (CF) excitations, ${ }^{19-24}$ but also extensively by Güdel and coworkers for directly probing the exchange manifold in the study of simple Ln dimers. ${ }^{25-30}$ EPR has long been used to interrogate weak magnetic interactions for dand f-block systems, ${ }^{31-34}$ and even temperature dependent nuclear magnetic resonance (NMR) has been used to correlate spectral linewidths to the occupation of ferro/antiferromagnetic exchange states (see ref. 35 for a comprehensive overview) and to predict SMM behavior. ${ }^{36-38}$

Our approach is to model the EPR spectra of the dimetallic species in the basis of the ground Kramers doublet of each ion, using the pseudo-spin $S=1 / 2$ formalism where the magnetic anisotropy of the doublet is given by the principal $g$-values. The magnetic exchange is then modelled by an effective anisotropic exchange Hamiltonian, Equation 1, where $\overline{\bar{J}}$ is the generalized exchange matrix and $\overline{\bar{g}}_{i}$ are the effective $g$-matrices for each site, all expressed in a common reference frame. ${ }^{25-29}$ This approach is valid when the $C F$ is much larger than the magnetic exchange and Zeeman interactions.

$\widehat{H}=-2 \overrightarrow{\hat{S}}_{h q} \cdot \overline{\bar{J}} \cdot \overrightarrow{\hat{S}}_{N O_{3}}+\mu_{B}\left(\overrightarrow{\hat{S}}_{h q} \cdot \overline{\bar{g}}_{h q}+\overrightarrow{\hat{S}}_{\mathrm{NO}_{3}} \cdot \overline{\bar{g}}_{N O_{3}}\right) \cdot \vec{B}$

Even in this restricted basis, simulation of exchange coupled EPR spectra using this Hamiltonian is a challenging problem with numerous unknown parameters. For example, each Ln site requires six parameters for the principal $g$-values and orientations (to allow mapping of the principal axes to the molecular coordinates; one set of $g$-value orientations could be defined as a fixed reference frame if this information is not required), the exchange matrix could require nine parameters, and accounting for anisotropic linewidths across S-, X- and Q-band frequencies results in a total of 30 parameters. Therefore, we attempt to reduce the number of free parameters by defining as many as possible with experimental data.

\section{Results}

To model the magnetic interactions within the dimetallic compounds, we employ the following approach (Scheme 1). Firstly, we collect low temperature EPR spectra for dilute species to determine the effective $g$-values of the ground Kramers doublets intrinsic to each site (see SI section 8 , for details of the connection between the effective $S=1 / 2 g$-matrix and the $m_{J}$ states of $\mathrm{Ln}(\mathrm{III})$ ions). As the $\mathrm{Ln}_{2}$ family is isostructural, solidstate dilution experiments in Y(III) or Lu(III) host lattices isolate paramagnetic $\mathrm{Er}(\mathrm{III})$ or $\mathrm{Yb}$ (III) dopants in the two unique pockets of the dimer. The smaller Ln pocket coordinates four hq ligands (hq pocket), where three of the oxygen donors bridge to the second site, which is capped by three $\mathrm{NO}_{3}$ anions $\left(\mathrm{NO}_{3}\right.$ pocket); the volume of the coordination polyhedron is $\sim 8 \%$ larger for the $\mathrm{NO}_{3}$ pocket than the hq pocket (Table S1). Therefore, when the dopant is smaller than the host, the dopant occupies the hq pocket preferentially, and vice-versa. Dilute samples are prepared with $\sim 5 \%$ dopant during synthesis (see ref. 18 for synthetic procedure), which we refer to $\mathrm{Ln} @ \mathrm{Y}_{2}$ or $\mathrm{Ln} @ \mathrm{Lu}_{2}$, as appropriate. EPR spectra at $5 \mathrm{~K}$ at S-, X- and Q-band frequencies (ca. 3.8, 9.4 and $34 \mathrm{GHz}$, respectively) for these diluted species show resonances owing to the hq and/or $\mathrm{NO}_{3}$ pockets; one or both pockets may be occupied depending on the dopant and the host, but no signals from paramagnetic dimetallic molecules are observed. Simultaneous modelling of these spectra using $\mathrm{PHI}^{39}$ or EasySpin $^{40}$ with a pseudo-spin $S=1 / 2 \operatorname{model}\left(\widehat{H}=\mu_{B} \hat{S} \cdot \overline{\bar{g}} \cdot \vec{B}\right)$ yields the effective $g$-values for the ground Kramers doublet of each pocket.

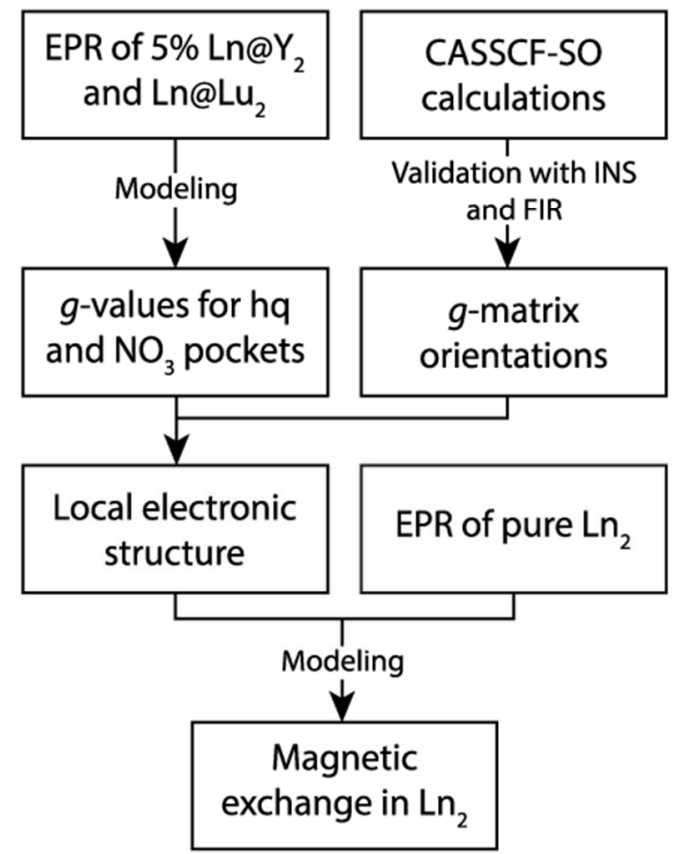

Scheme 1. Procedure for determining magnetic exchange in $\mathrm{Ln}_{2}$ dimetallic molecules. 
Secondly, we compare the dilute EPR results to CASSCF-SO calculations to identify the $g$-values belonging to each pocket; these calculations are performed on the $\mathrm{Ln}_{2}, \mathrm{Y}_{2}$ and $\mathrm{Lu}_{2}$ crystal structures to account for subtle structural changes between the lattices. Thirdly, we use INS and FIR spectroscopies to measure the $\mathrm{CF}$ energies of each pocket in the pure $\mathrm{Ln}_{2}$ species in order to validate the CASSCF-SO assignments. The exchange interactions are much smaller than the $\mathrm{CF}$ splittings and therefore these spectra show local CF excitations for each pocket; INS and FIR spectra of dilute samples are much too weak to obtain reliable data. INS excitations are shown to be magnetic in origin by comparison with the INS spectrum of the diamagnetic $\mathrm{Lu}_{2}$ analog, and likewise for FIR excitations by their magnetic field dependence.

Finally, we model the EPR spectra of the pure species to determine the magnetic exchange interactions using the following procedure: (i) we fix the effective $g$-values for each pocket from the dilution experiments (substituting missing data with CASSCF$\mathrm{SO}$ values where required). (ii) We fix the orientations of the principal $g$-values with respect to the molecular structure with the CASSCF-SO-calculated values. We define the $g$-matrix for each pocket with Equation 2, where the rotation matrix is defined as Equation 3; for convenience we use the orthogonalized $\mathrm{x}, \mathrm{y}, \mathrm{z}$ crystal axes as the global reference frame. (iii) We define the orientations of the principal components of the exchange matrix in the orthogonalized reference frame (Equation 4), where we choose $J_{z}$ to lie along the internuclear $\operatorname{Ln}-\operatorname{Ln}$ vector while $J_{x}$ and $J_{y}$ have a flexible rotation around $J_{z}$ (this defines $\alpha_{e x}=54.5^{\circ}$ and $\beta_{e x}=81.3^{\circ}$ while the $\gamma_{e x}$ rotation around $J_{z}$ becomes a fitting parameter of the model).

With $\gamma_{e x}=0^{\circ}$ fixed, combinations of $J_{x}, J_{y}$ and $J_{z}$ each in the range -1 to $+1 \mathrm{~cm}^{-1}$ are examined (chosen to encompass the exchange state observed by INS at $c a .0 .6 \mathrm{~cm}^{-1}$, see below) by simulation of the EPR spectra with PHI. Goodness-of-fit quantification for EPR spectroscopy is notoriously difficult, thus numerical least-squares residuals must be tempered with side-byside visual comparisons. Examining this parameter space yields numerous local minima, which are subsequently investigated by direct fitting of the EPR spectra including examining the full rotation of $\gamma_{e x}$, to determine the best global fit. Further refinement of the model allowing flexibility in the local rotations of the principal $g$-values is achieved through an iterative approach by alternating between free parameters.
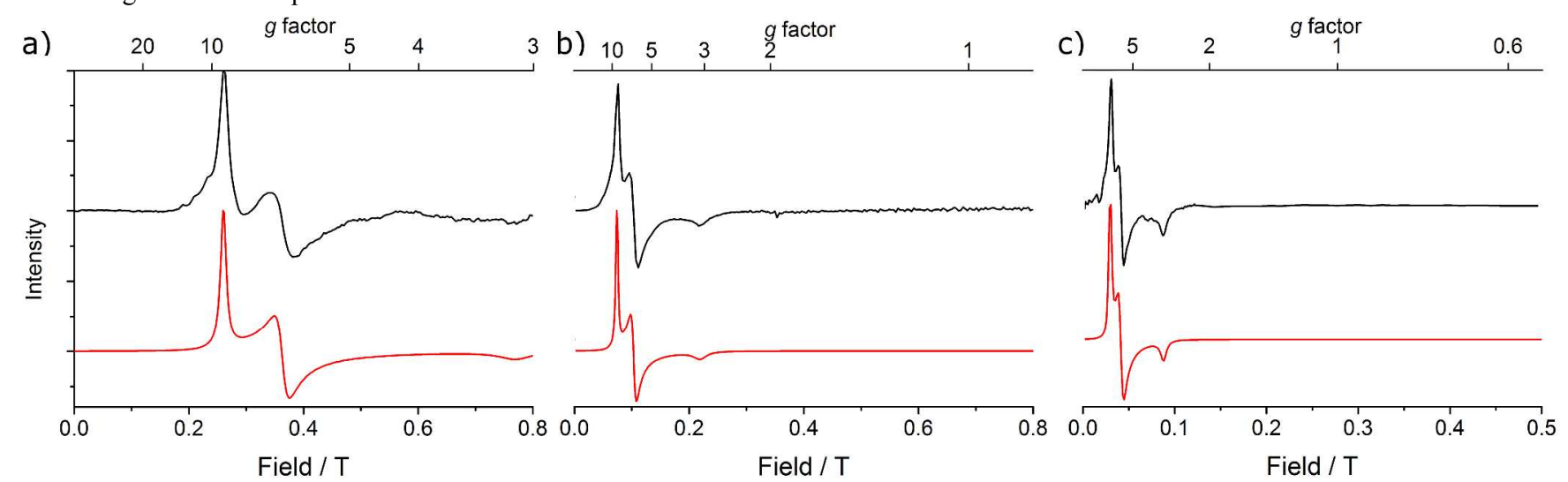

Figure 2. EPR spectra (black) and simulations (red) for Er@Lu collected at $5 \mathrm{~K}$ and (a) Q-band $34.055 \mathrm{GHz}$, (b) X-band 9.543 GHz and (c) S-band $3.875 \mathrm{GHz}$. Simulations performed with PHI with parameters: $g_{1}=9.5, \mathrm{~g}_{2}=6.8$ and $\mathrm{g}_{3}=3.2, \mathrm{lw}_{\mathrm{x}}=3.0, \mathrm{lw}_{\mathrm{y}}=2.5$ and $\mathrm{lw}_{\mathrm{z}}=1.5$ GHz for Q-band, $\mathrm{lw}_{\mathrm{x}}=1.2, \mathrm{lw}_{\mathrm{y}}=0.9$ and $\mathrm{lw}_{\mathrm{z}}=0.5 \mathrm{GHz}$ for X-band and $\mathrm{lw}_{\mathrm{x}}=0.3, \mathrm{lw}_{\mathrm{y}}=0.5$ and $\mathrm{lw}_{\mathrm{z}}=0.3 \mathrm{GHz}$ for S-band.

$$
\begin{aligned}
\overline{\bar{g}}_{i} & =\overline{\bar{R}} \cdot\left[\begin{array}{ccc}
g_{1} & 0 & 0 \\
0 & g_{2} & 0 \\
0 & 0 & g_{3}
\end{array}\right] \cdot \overline{\bar{R}}^{T} \\
& \overline{\bar{R}}=\left[\begin{array}{ccc}
\cos \alpha & -\sin \alpha & 0 \\
\sin \alpha & \cos \alpha & 0 \\
0 & 0 & 1
\end{array}\right]\left[\begin{array}{ccc}
\cos \beta & 0 & \sin \beta \\
0 & 1 & 0 \\
-\sin \beta & 0 & \cos \beta
\end{array}\right]\left[\begin{array}{ccc}
\cos \gamma & -\sin \gamma & 0 \\
\sin \gamma & \cos \gamma & 0 \\
0 & 0 & 1
\end{array}\right]
\end{aligned}
$$

$\overline{\bar{J}}=\overline{\bar{R}} \cdot\left[\begin{array}{ccc}J_{x} & 0 & 0 \\ 0 & J_{y} & 0 \\ 0 & 0 & J_{z}\end{array}\right] \cdot \overline{\bar{R}}^{T}$

\section{$\left[h q \mathrm{H}_{2}\right]\left[\mathrm{Er}_{2}(h q)_{4}\left(\mathrm{NO}_{3}\right)_{3}\right] \cdot \mathrm{MeOH}\left(\mathrm{Er}_{2}\right)$}

The $\chi_{M} T$ product for $\mathrm{Er}_{2}$ has a room temperature value of $22.9 \mathrm{~cm}^{3}$ $\mathrm{mol}^{-1} \mathrm{~K}$ which is in good agreement for two ${ }^{4} \mathrm{I}_{15 / 2} \mathrm{Er}(\mathrm{III})$ ions $\left(23.0 \mathrm{~cm}^{3} \mathrm{~mol}^{-1} \mathrm{~K}\right)$. The curve shows minimal features, with the usual decrease at lower temperatures a result of depopulation of excited CF states (Figure S1). The magnetization data collected at 2,4 , and $6 \mathrm{~K}$ do not saturate up to $7 \mathrm{~T}$, indicating strong magnetic anisotropy (Figure S1); these data show no direct evidence of magnetic interactions. Alternating current (AC) susceptibility measurements in zero applied field show no out-of-phase signals below $20 \mathrm{~K}$, and thus $\mathrm{Er}_{2}$ is not an SMM (Figure S2).

EPR spectra at X- and Q-band for Er@, $\mathrm{Y}_{2}$ reveal two wellresolved features that overlap in the S-band spectrum (Figure S3). Simultaneous modelling of these spectra gives $g_{1}=9.9$ and $g_{2}=$ 6.6; we do not observe $g_{3}$. As $\operatorname{Er}(\mathrm{III})$ and Y(III) have similar ionic radii, ${ }^{41,42}$ we would expect the Er(III) dopant to be distributed across both pockets, and thus it is not clear why only a single set of $g$-values is observed here; this observation has been made for multiple sample batches. EPR spectra for $\mathrm{Er} @ \mathrm{Lu}_{2}$ show three well-separated features at all three frequencies (Figure 2), which can be modelled with $g_{1}=9.5, g_{2}=6.8$ and $g_{3}=3.2$. Interestingly, the two dilution experiments yield very similar $g_{1}$ and $g_{2}$ values and it appears that the same site is being observed despite the different host lattices. This could be a result of: (i) only one site being occupied in both experiments, (ii) one site has very fast spin-lattice relaxation and thus is broadened beyond detection, or (iii) one site has a significantly weaker signal. 
CASSCF-SO calculations predict very different ground Kramers doublets for the two pockets (Tables 1 and S3). The ground doublet for the hq pocket is well-isolated $\left(32.4 \mathrm{~cm}^{-1}\right.$ to first excited state), while the $\mathrm{NO}_{3}$ pocket has a low-lying excited state at $7.3 \mathrm{~cm}^{-1}$. The calculations employing different host structures indicate that the electronic structure of $\operatorname{Er}(\mathrm{III})$ is very sensitive to minor variations in geometry and that the $\mathrm{NO}_{3}$ pocket for both $\mathrm{Er} @ \mathrm{Y}_{2}$ and $\mathrm{Er} @ \mathrm{Lu}_{2}$ calculations matches well with the experimental $g$-values. The only missing experimental feature is $g_{3}=3.5$ in the Er@Y $Y_{2}$ spectra, which could be broadened beyond detection for this sample. Given the good agreement with theory, and the similarity of $g_{1}$ and $g_{2}$ between the Er@ $@ \mathrm{Y}_{2}$ and $\operatorname{Er} @ \mathrm{Lu}_{2}$ experiments, we suggest that the $\mathrm{NO}_{3}$ pocket is observed in both experiments. It is important to note that due to the low-lying excited state for the $\mathrm{NO}_{3}$ pocket, it is possible that contributions from this excited state could be observed in the EPR spectra even at $5 \mathrm{~K}$; however, the experimental data show no evidence of excited state transitions.

Table 1. Principal $g$-values from CASSCF-SO calculations for $\mathrm{Er}(\mathrm{III})$ in both pockets using the $\mathrm{Er}_{2}, \mathrm{Y}_{2}$ and $\mathrm{Lu}_{2}$ crystal structures. Orange row = assignment for $\mathrm{Er} @ \mathrm{Y}_{2}$, green row = assignment for $\mathrm{Er} @ \mathrm{Lu}_{2}$.

\begin{tabular}{|c|c|c|c|}
\hline Structure & $\boldsymbol{g}_{\mathbf{1}}$ & $\boldsymbol{g}_{\mathbf{2}}$ & $\boldsymbol{g}_{\mathbf{3}}$ \\
\hline \multicolumn{4}{|c|}{ hq pocket } \\
\hline $\mathbf{E} \mathbf{r}_{\mathbf{2}}$ & 13.3 & 4.3 & 0.6 \\
\hline $\mathbf{E r} @ \mathbf{Y}_{\mathbf{2}}$ & 13.2 & 4.3 & 0.4 \\
\hline $\mathbf{E r} @ \mathbf{L u}_{\mathbf{2}}$ & 14.3 & 3.2 & 0.5 \\
\hline \multicolumn{5}{|c|}{$\mathbf{N O}_{\mathbf{3}}$ pocket } \\
\hline $\mathbf{E} \mathbf{r}_{\mathbf{2}}$ & 11.8 & 3.8 & 2.2 \\
\hline $\mathbf{E r} @ \mathbf{Y}_{\mathbf{2}}$ & 9.0 & 7.1 & 3.5 \\
\hline $\mathbf{E r} @ \mathbf{L u}_{\mathbf{2}}$ & 9.3 & 6.4 & 4.0 \\
\hline
\end{tabular}

INS spectra collected at an incident energy $\left(E_{\mathrm{i}}\right)$ of $120 \mathrm{~cm}^{-1}$ $(15 \mathrm{meV})$ show well-resolved magnetic features at $12(2)$ (subsequently confirmed at $11.7 \mathrm{~cm}^{-1}$, Figure S5), 32.0(7), and $102(2) \mathrm{cm}^{-1}$ (1.50(2), 3.97(8), and 12.6(2) meV); with $E_{\mathrm{i}}=200 \mathrm{~cm}^{-1}(25 \mathrm{meV})$, two more relatively weak features at $130(3)$ and $148(2) \mathrm{cm}^{-1}(16.1(4)$ and $18.3(3) \mathrm{meV})$ are detected (Figures 3 and S4). Some weaker signals are also found around 233 and $290 \mathrm{~cm}^{-1}$.

Simulation of the INS spectra utilizing the CASSCF-SOcalculated CF parameters (CFPs, ${ }^{43}$ Table S4) with the Mantid program ${ }^{44}$ shows that the 32.0 and $102 \mathrm{~cm}^{-1}(3.97$ and $12.6 \mathrm{meV})$ features arise from the hq pocket (Figures 3 and S6). The peaks are predicted in both position and relative intensity, and correspond to transitions to the first and second excited states, respectively. The remaining features at $11.7,130$ and $148 \mathrm{~cm}^{-1}$ $(1.45,16.1$ and $18.3 \mathrm{meV})$ must be due to the $\mathrm{NO}_{3}$ pocket, however, a simple scaling factor of 1.5 is needed to bring the calculated energies from CASSCF-SO into agreement with the experimental positions, with excellent prediction of the intensity ratios (Figures S8 and S9). Scaling ab initio energies is common to aid interpretation of INS and FIR data ${ }^{18,20,26}$ however we were curious why this was required for the $\mathrm{NO}_{3}$ pocket and not for the hq pocket. We have found that CASSCF-SO calculations on the isolated $\left[\mathrm{Er}_{2}(\mathrm{hq})_{4}\left(\mathrm{NO}_{3}\right)_{3}\right]^{-}$anion are insufficient to describe the subtle electrostatic environment of the $\mathrm{NO}_{3}$ pocket, and that simulation of a more realistic crystal lattice using point charges brings the ab-initio calculated energies closer to the experimental data (Table S5) thus explaining the scaling factor (see SI section 3 for details). Further confirming these results, FIR spectroscopy shows two clear magnetic transitions at $32 \mathrm{~cm}^{-1}$ and $102 \mathrm{~cm}^{-1}$ (3.97 and $12.6 \mathrm{meV}$, Figure S10), in excellent agreement with INS transitions originating from the hq pocket.
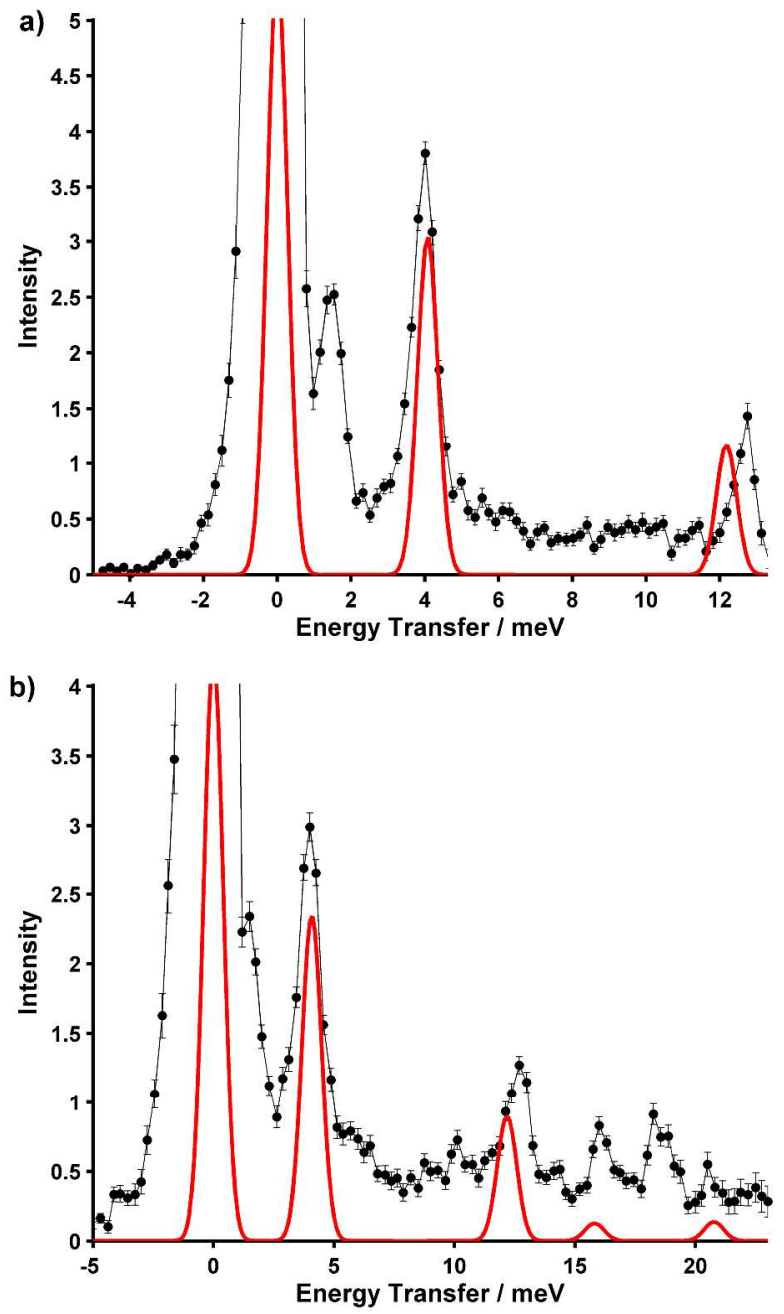

Figure 3. INS spectra for $\mathrm{Er}_{2}$ after phonon background $\left(\mathrm{Lu}_{2}\right)$ subtracted with simulated INS spectrum for the hq pocket based on ab initio CFPs. a) $120 \mathrm{~cm}^{-1}(15 \mathrm{meV})$ and b) $200 \mathrm{~cm}^{-1}(25$ $\mathrm{meV}$ ) incident energies with data integrated from $0<|\mathrm{Q}|<3 \AA^{-1}$.

To obtain an order-of-magnitude estimate for the magnetic exchange interaction in the pure $\mathrm{Er}_{2}$ species, close inspection of the elastic line in the low-energy $\left(14.88 \mathrm{~cm}^{-1}, 1.845 \mathrm{meV}\right)$ INS data shows evidence of a small shoulder. Further measurements at $E_{\mathrm{i}}=8.1 \mathrm{~cm}^{-1}(1.0 \mathrm{meV})$ reveals a broad, cold transition at $0.6 \mathrm{~cm}^{-1}$ $(0.07 \mathrm{meV}$, Figure S11), which we assign as transitions within the low-lying exchange manifold of $\mathrm{Er}_{2}$. 
a)

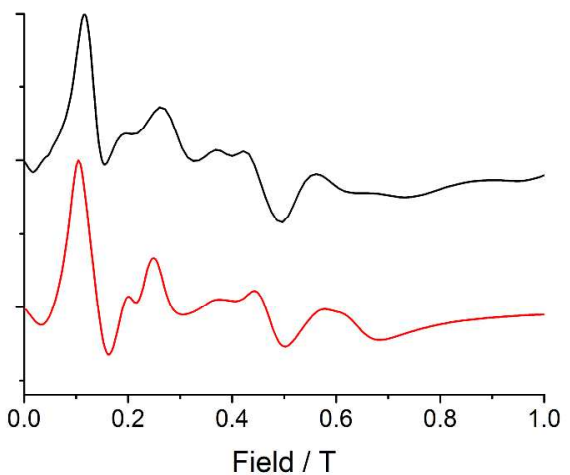

b)

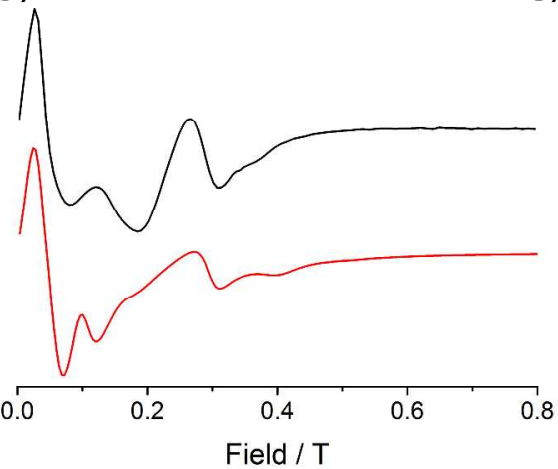

c)

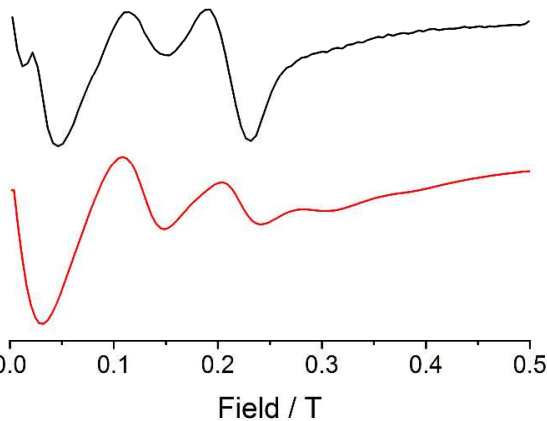

Figure 4. EPR spectra (black) and simulations (red) for $\mathrm{Er}_{2}$ collected at $5 \mathrm{~K}$ and (a) Q-band $33.980 \mathrm{GHz}$, (b) X-band $9.5426 \mathrm{GHz}$ and (c) S-band $3.8744 \mathrm{GHz}$. Simulations performed with PHI using parameters in Table 2.

EPR spectra collected at S-, X- and Q-band of $\mathrm{Er}_{2}$ (Figure 4) are highly featured and clearly distinct from the dilute species, providing direct information on the magnetic interactions within the $\mathrm{Er}_{2}$ molecule. The three principal $g$-values of the $\mathrm{NO}_{3}$ pocket are defined as $g_{1}=9.5, g_{2}=6.8$ and $g_{3}=3.2$ (from $\operatorname{Er} @ \mathrm{Lu}_{2}$ where all $g$-values are observed). As we are unable to observe the $g$ values for the hq pocket, these are fixed from CASSCF-SO calculations on the $\mathrm{Er}_{2}$ structure: $g_{1}=13.3, g_{2}=4.3$ and $g_{3}=0.6$.

With the orientations of the $g$-matrices for each site fixed from CASSCF-SO (Table S6), exploration of the parameter space as described yielded one clear global minimum for $J_{x}=-0.07 \mathrm{~cm}^{-1}$, $J_{y}=0.4 \mathrm{~cm}^{-1}, J_{z}=0.7 \mathrm{~cm}^{-1}$ and $\gamma_{e x}=9^{\circ}$. Refinement of the model gives excellent agreement with the experimental EPR spectra across all three frequencies (Figure 4 and Table 2), as well as good agreement with the low temperature magnetic data (Figure S15). Our data are not sensitive to the overall sign of the exchange matrix, and thus an equally good reproduction of the data can be obtained with $-\overline{\bar{J}}$ (Figures S15 and S16); however, the data are sensitive to the relative signs of the exchange parameters. High frequency EPR (HF-EPR) between 260 and $380 \mathrm{GHz}$ is in good agreement with the model determined at low frequencies (Figure S17). Interestingly, there is a near-zero-field resonance in the 310 and $345 \mathrm{GHz}$ spectra; this suggests the presence of a state at $c a$. $10-11 \mathrm{~cm}^{-1}(1.3-1.4 \mathrm{meV})$, which is coincident with the first excited state for the $\mathrm{NO}_{3}$ pocket determined to lie at $11.7 \mathrm{~cm}^{-1}$ $(1.45 \mathrm{meV})$ from the INS data.

Table 2. Optimized parameters for the simulation of $\mathrm{Er}_{2} \mathrm{EPR}$ spectra.

\begin{tabular}{|c|c|c|c|}
\hline \multirow[t]{2}{*}{ Parameter } & \multicolumn{3}{|c|}{ Value(s) } \\
\hline & $J_{x}\left(\mathrm{~cm}^{-1}\right)$ & $J_{y}\left(\mathrm{~cm}^{-1}\right)$ & $J_{z}\left(\mathrm{~cm}^{-1}\right)$ \\
\hline$\overline{\bar{J}}$ & -0.057 & 0.45 & 0.72 \\
\hline & $g_{1}$ & $g_{2}$ & $g_{3}$ \\
\hline$\overline{\bar{g}}_{h q}($ fixed $)$ & 13.3 & 4.3 & 0.6 \\
\hline$\overline{\bar{g}}_{N O_{3}}($ fixed) & 9.5 & 6.8 & 3.2 \\
\hline & $\alpha\left({ }^{\circ}\right)$ & $\beta\left({ }^{\circ}\right)$ & $\gamma\left({ }^{\circ}\right)$ \\
\hline
\end{tabular}

\begin{tabular}{|c|c|c|c|}
\hline $\boldsymbol{R}\left(\overline{\bar{g}}_{\boldsymbol{h q}}\right)$ & -54.9 & -80.0 & -110 \\
\hline $\boldsymbol{R}\left(\overline{\bar{g}}_{\boldsymbol{N o}}\right)$ & 3.69 & 169 & 45.0 \\
\hline $\boldsymbol{R}(\overline{\bar{J}})$ & 54.5 (fixed) & 81.3 (fixed) & 8.85 \\
\hline & $\mathbf{~ w w ~}_{\mathbf{x}}(\mathbf{G H z})$ & $\mathbf{I w}_{\mathbf{y}}(\mathbf{G H z})$ & $\mathbf{~ w w ~}_{\mathbf{z}}(\mathbf{G H z})$ \\
\hline Q-band & 4.3 & 5.1 & 7.9 \\
\hline X-band & 5.0 & 5.0 & 3.0 \\
\hline S-band & 2.5 & 4.0 & 5.5 \\
\hline
\end{tabular}

\section{$\left[\mathrm{hqH} \mathrm{H}_{2}\right]\left[\mathrm{Yb}_{2}(\mathrm{hq})_{4}\left(\mathrm{NO}_{3}\right)_{3}\right] \cdot \mathrm{MeOH}\left(\mathrm{Yb}_{2}\right)$}

The magnetic susceptibility for $\mathrm{Yb}_{2}$ has a room temperature $\chi_{M} T$ value of $5.01 \mathrm{~cm}^{3} \mathrm{~mol}^{-1} \mathrm{~K}$ which is in good agreement with the expected $\chi_{M} T$ value of $5.14 \mathrm{~cm}^{3} \mathrm{~mol}^{-1} \mathrm{~K}$ for two $\mathrm{Yb}(\mathrm{III}){ }^{2} \mathrm{~F}_{7 / 2}$ ground terms (Figure S22). $\chi_{M} T$ shows a gradual decrease with decreasing temperature originating from depopulation of excited $\mathrm{CF}$ states. Magnetization data at $2 \mathrm{~K}$ almost saturate at $7 \mathrm{~T}$ to a value of $3.54 N_{A} \mu_{B}$, (Figure S22) with no evidence of magnetic exchange in the $\chi_{M} T$ or magnetization data. AC susceptibility measurements show no out-of-phase signal revealing $\mathrm{Yb}_{2}$ is not an SMM (Figure S23).

EPR spectra of $\mathrm{Yb} @ \mathrm{Y}_{2}$ show two resonances with hyperfine structure at S-, X- and Q-band (Figure 5). Modelling these spectra gives $g_{1}=5.9$ and $g_{2}=1.8$ while no $g_{3}$ feature was observed. The hyperfine coupling was fixed for the ${ }^{171 / 173} \mathrm{Yb}$ nuclei to the linear relationship based on the $g$-values as determined by Denning et al. (for ${ }^{171} \mathrm{Yb}: A_{i}=796 g_{i}-43$ and ${ }^{173} \mathrm{Yb}: A_{i}=232 g-18$, thus $A_{1}=1344$ and $4630 \mathrm{MHz}, A_{2}=397$ and $1382 \mathrm{MHz}$, for ${ }^{173} \mathrm{Yb}$ and ${ }^{171} \mathrm{Yb}$, respectively). ${ }^{45} \mathrm{EPR}$ spectra of $\mathrm{Yb} @ \mathrm{Lu}_{2}$ reveal two welldefined $g_{1}$ features, two $g_{2}$ features and a weak, broad $g_{3}$ feature (Figure S24); hyperfine interactions are not resolved here. Modelling the $\mathrm{Yb} @ \mathrm{Lu}_{2}$ spectra as two non-interacting $S=1 / 2$ states with $g$-values of $g_{1}=5.0, g_{2}=2.7$ and $g_{3}=1.1$, and $g_{1}=5.9$ and $g_{2}=1.7$ for each doublet, respectively, provides excellent agreement with the experimental data. We do not observe $g_{3}$ for one of the pockets. 

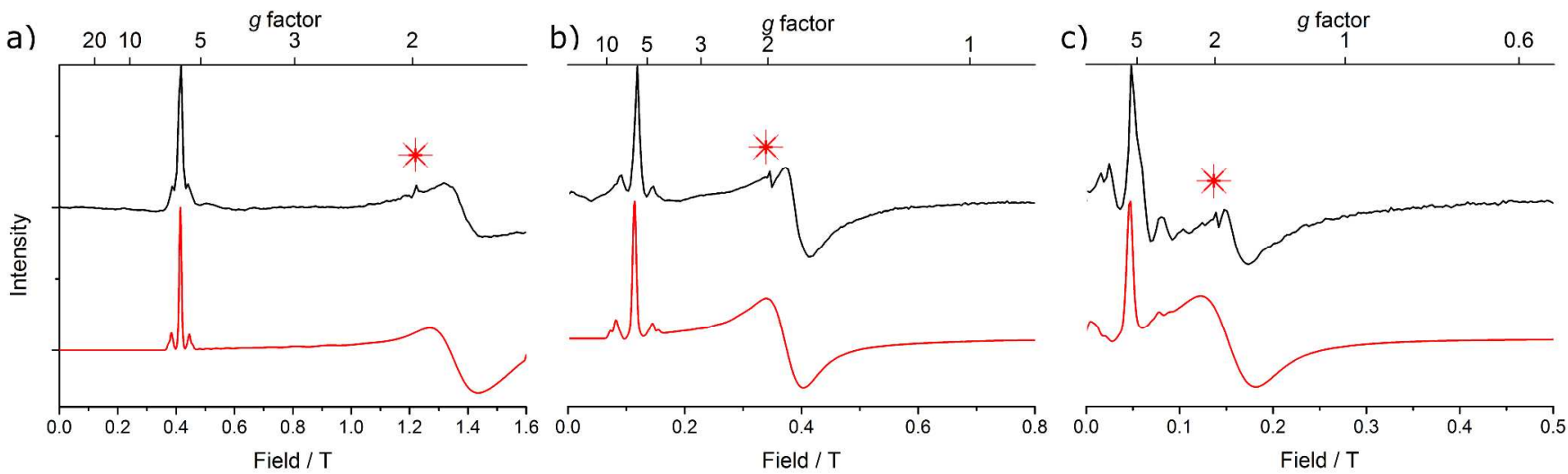

Figure 5. EPR spectra (black) and simulations (red) for $\mathrm{Yb} @ \mathrm{Y}_{2}$ collected at $5 \mathrm{~K}$ and (a) Q-band $34.095 \mathrm{GHz}$, (b) X-band $9.733 \mathrm{GHz}$ and (c) S-band $3.874 \mathrm{GHz}$. Simulations performed with EasySpin taking into account nuclear spin for ${ }^{171} \mathrm{Yb}$ and ${ }^{173} \mathrm{Yb}$, using parameters: $g_{1}=$ 5.87, $\mathrm{g}_{2}=1.79$ and $\mathrm{g}_{3}=0.1$ (not observed), $\mathrm{H}$-strain $=430,1300$ and $1300 \mathrm{MHz}$ for Q-, X- and S-band, respectively, and lw $=4.7 \mathrm{mT}$ (FWHW). *Peak arising at $\mathrm{g} \approx 2$ from impurities in the EPR tube.

As the $\mathrm{Yb} @ \mathrm{Y}_{2}$ experiment should be selective for the hq pocket $(\mathrm{Yb}(\mathrm{III})$ is smaller than $\mathrm{Y}(\mathrm{III}))$, we assign $g_{l}=5.9$ and $g_{2}=1.8$ to this pocket. Therefore, the resonances in the $\mathrm{Yb} @ \mathrm{Lu}_{2}$ sample at $g_{1}$ $=5.0, g_{2}=2.7$ and $g_{3}=1.1$ can be assigned to the $\mathrm{NO}_{3}$ pocket. The shift in $g_{2}$ for the hq pocket between $\mathrm{Yb} @ \mathrm{Y}_{2}$ and $\mathrm{Yb} @ \mathrm{Lu}_{2}$ is worth noting, and compares well to the variations observed in CASSCF-SO calculations (Tables 3 and S8). These calculations show that both pockets for $\mathrm{Yb}_{2}$ have well isolated ground states with no excited state signals expected in the $5 \mathrm{~K}$ EPR measurements. The CASSCF-SO-calculated $g$-values for the hq pocket of $\mathrm{Yb} @ \mathrm{Y}_{2}\left(g_{1}=6.2, g_{2}=2.1\right.$ and $\left.g_{3}=0.5\right)$ are in good agreement with the $\mathrm{Yb} @ \mathrm{Y}_{2}$ experimental data $\left(g_{1}=5.9\right.$ and $g_{2}=$ $1.8, g_{3}$ not observed), and the calculated g-values for the $\mathrm{NO}_{3}$ pocket of $\mathrm{Yb} @ \mathrm{Lu}_{2}\left(g_{1}=5.8, g_{2}=2.4\right.$ and $\left.g_{3}=1.0\right)$ are also in good agreement with the experimentally observed values of $g_{1}=$ $5.0, g_{2}=2.7$ and $g_{3}=1.1$.

Table 3. Principal $g$-values from CASSCF-SO calculations for $\mathrm{Yb}(\mathrm{III})$ in both pockets using the $\mathrm{Yb}_{2}, \mathrm{Y}_{2}$ and $\mathrm{Lu}_{2}$ crystal structures. Orange row $=$ assignment for $\mathrm{Yb} @ \mathrm{Y}_{2}$, green rows $=$ assignment for $\mathrm{Yb} @ \mathrm{Lu}_{2}$.

\begin{tabular}{|c|c|c|c|}
\hline Structure & $\boldsymbol{g}_{\mathbf{1}}$ & $\boldsymbol{g}_{\mathbf{2}}$ & $\boldsymbol{g}_{\mathbf{3}}$ \\
\hline \multicolumn{4}{|c|}{ hq pocket } \\
\hline $\mathbf{Y b}_{\mathbf{2}}$ & 6.3 & 1.9 & 0.5 \\
\hline $\mathbf{Y b} @ \mathbf{Y}_{\mathbf{2}}$ & 6.2 & 2.1 & 0.5 \\
\hline $\mathbf{Y b} @ \mathbf{L u} \mathbf{u}_{\mathbf{2}}$ & 6.5 & 1.6 & 0.4 \\
\hline \multicolumn{4}{|c|}{$\mathbf{N O}_{\mathbf{3}}$ pocket } \\
\hline $\mathbf{Y b}_{\mathbf{2}}$ & 4.9 & 3.7 & 1.0 \\
\hline $\mathbf{Y b} @ \mathbf{Y}_{\mathbf{2}}$ & 4.7 & 3.6 & 1.2 \\
\hline $\mathbf{Y b} @ \mathbf{L} \mathbf{u}_{\mathbf{2}}$ & 5.8 & 2.4 & 1.0 \\
\hline
\end{tabular}

INS spectra of $\mathrm{Yb}_{2}$ reveal only weak magnetic signals over the $\mathrm{Lu}_{2}$ background (Figure S25); simulations of the INS transitions with the CASSCF-SO CFPs show that $\mathrm{Yb}_{2}$ is predicted to have ca. $75 \%$ weaker absolute intensity than $\mathrm{Er}_{2}$ when comparing the most intense transitions (Figure S26), explaining the weaker experimental spectra for $\mathrm{Yb}_{2}$. The noisy data make it difficult to assign peaks, but there are broad signals present between $24-80$ $\mathrm{cm}^{-1}(3-10 \mathrm{meV}), 160-240 \mathrm{~cm}^{-1}(20-30 \mathrm{meV})$ and $290 \mathrm{~cm}^{-1}$ $(36 \mathrm{meV}$ ). Simulations (CFPs in Table S9) predict features at 40, 129 and $240 \mathrm{~cm}^{-1}(5.0,16.0$ and $31.0 \mathrm{meV})$ originating from the $\mathrm{NO}_{3}$ pocket (Figure S28), and one strong feature at $160 \mathrm{~cm}^{-1}(19.8$ $\mathrm{meV}$ ) for the hq pocket (Figure S27). These features are broadly consistent with the limited experimental data.

In contrast, FIR spectra for $\mathrm{Yb}_{2}$ show a clear feature at $64 \mathrm{~cm}^{-1}$ ( $8 \mathrm{meV}$, Figure 6), likely corresponding to the CASSCF-SOpredicted transition at $40 \mathrm{~cm}^{-1}$ from the $\mathrm{NO}_{3}$ pocket (Table S8). Similarly to $\mathrm{Er}_{2}$, we observe a discrepancy between the calculated and experimentally observed $\mathrm{CF}$ states for the $\mathrm{NO}_{3}$ pocket; the appropriate scaling factor in this case is 1.6 , nearly identical to that for $\mathrm{Er}_{2}$, and thus we suspect this is also due to the poor description of the electrostatic potential in CASSCF-SO calculations of the isolated molecule. Applying this scaling factor to the $\mathrm{NO}_{3}$ pocket CFPs (Figure S29) results in a good overall reproduction of the experimental INS data (Figure S30).

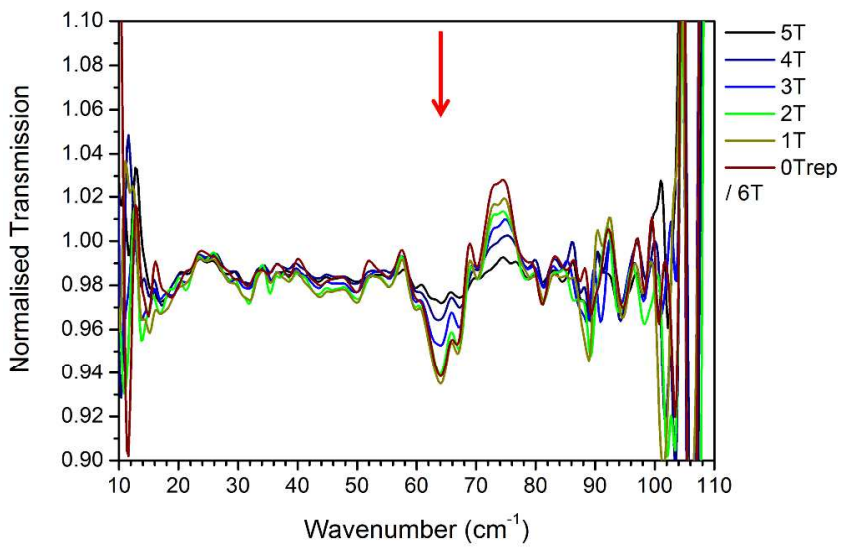

Figure 6: Far-IR transmission spectra of $\mathrm{Yb}_{2}$ normalized to the $6 \mathrm{~T}$ data at $9 \mathrm{~K}$. Field-dependent peak is marked by a red arrow for clarity. 
a)

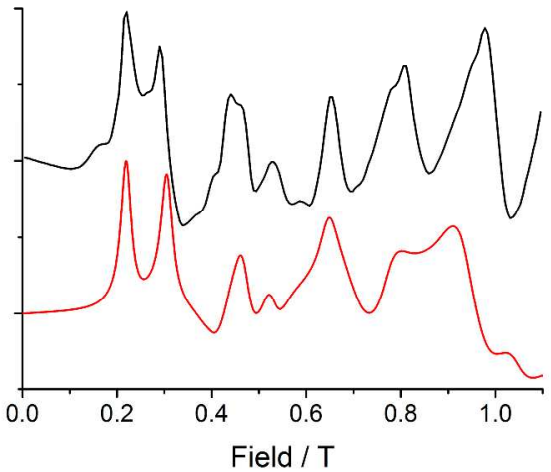

b)

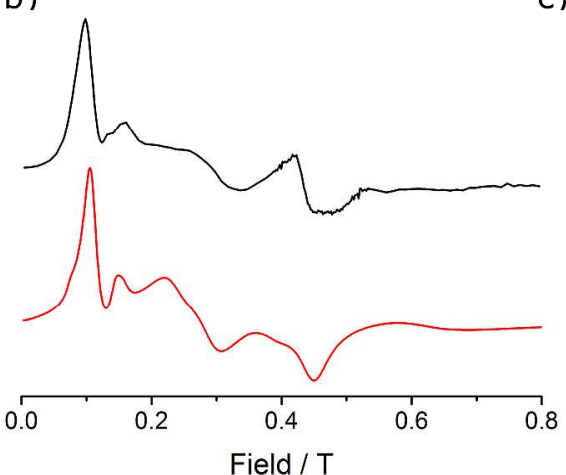

c)

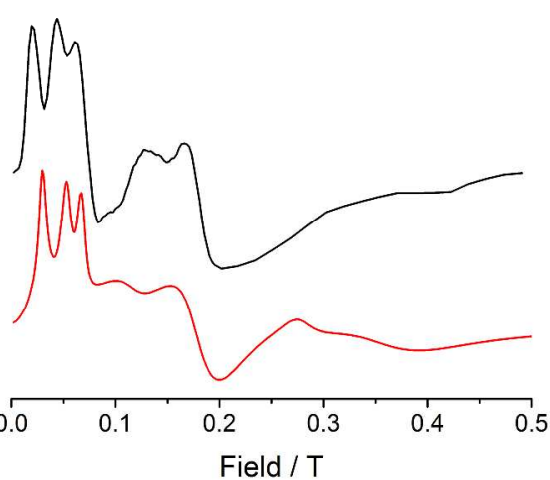

Figure 7. EPR spectra (black) and simulations (red) for $\mathrm{Yb}_{2}$ collected at $5 \mathrm{~K}$ and (a) Q-band $34.074 \mathrm{GHz}$, (b) X-band $9.564 \mathrm{GHz}$ and (c) S-band $3.875 \mathrm{GHz}$. Simulations performed with PHI using parameters in Table 4.

EPR spectra of the pure $\mathrm{Yb}_{2}$ species measured at S-, X- and Qband and $5 \mathrm{~K}$ are highly structured (Figure 7). Each pocket is assigned their experimentally observed $g$-values (hq pocket: $g_{1}=$ $5.9, g_{2}=1.8$ and $g_{3}=0.5-g_{3}$ fixed from CASSCF-SO for $\mathrm{Yb}_{2}$; $\mathrm{NO}_{3}$ pocket: $g_{1}=5.0, g_{2}=2.7$ and $\left.g_{3}=1.1\right)$ and their orientations fixed from CASSCF-SO (Table S10). Initial surveys of the exchange parameters yielded a clear best-fit for $J_{x}=-0.25 \mathrm{~cm}^{-1}$, $J_{y}=0.25 \mathrm{~cm}^{-3}$ and $J_{z}=-0.30 \mathrm{~cm}^{-1}$. Allowing freedom for $g$-matrix rotations and variable $\gamma_{e x}$ results in an excellent simulation of all features across S-, X- and Q-band (Figure 7) as well as excellent reproduction of the low temperature magnetic data (Figure S33) with parameters given in Table 4. Again, the simulations are insensitive to the absolute sign of the exchange matrix with an inversion yielding a simulation of equal quality (Figures S33 and S34).

Table 4. Optimized parameters for simulation of $\mathrm{Yb}_{2}$ EPR spectra.

\begin{tabular}{|c|c|c|c|}
\hline Parameter & \multicolumn{3}{|c|}{ Value(s) } \\
\hline & $J_{x}\left(\mathrm{~cm}^{-1}\right)$ & $J_{y}\left(\mathrm{~cm}^{-1}\right)$ & $J_{z}\left(\mathrm{~cm}^{-1}\right)$ \\
\hline$\overline{\bar{J}}$ & -0.25 & 0.25 & -0.29 \\
\hline & $g_{1}$ & $g_{2}$ & $g_{3}$ \\
\hline$\overline{\bar{g}}_{h q}($ fixed $)$ & 5.9 & 1.8 & 0.5 \\
\hline$\overline{\bar{g}}_{N O_{3}}$ (fixed) & 5.0 & 2.7 & 1.1 \\
\hline & $\alpha\left({ }^{\circ}\right)$ & $\beta\left({ }^{\circ}\right)$ & $\gamma\left({ }^{\circ}\right)$ \\
\hline$R\left(\overline{\bar{g}}_{h q}\right)$ & -36.9 & -78.1 & 86.8 \\
\hline$R\left(\overline{\bar{g}}_{N O_{3}}\right)$ & 16.6 & -60.0 & 85.0 \\
\hline$R(\overline{\bar{J}})$ & 54.5 (fixed) & 81.3 (fixed) & 8.50 \\
\hline & $\operatorname{lw}_{\mathbf{x}}(\mathrm{GHz})$ & $\mathbf{l w}_{\mathbf{y}}(\mathbf{G H z})$ & $\mathbf{l w}_{\mathbf{z}}(\mathbf{G H z})$ \\
\hline Q-band & 2.9 & 1.6 & 3.5 \\
\hline X-band & 1.2 & 0.8 & 3.6 \\
\hline S-band & 0.4 & 1.2 & 2.2 \\
\hline
\end{tabular}

\section{Discussion}

Having simulated the rich EPR spectra of the pure dimetallic compounds, we have experimentally obtained detailed information on the low-lying states arising from magnetic exchange interactions. These experimental exchange states are benchmarking data for the generation of a transferable theoretical framework explaining Ln-Ln interactions. The exchange manifold in zero field for $\mathrm{Er}_{2}$ comprises four singlet states with an overall splitting of $1.1 \mathrm{~cm}^{-1}$, where all states are sufficiently mixed to yield non-zero magnetic moment transition matrix elements between each pair (Table S7). The profile of the relative magnetic moment transition intensities is generally in reasonable agreement with the lowest energy experimental INS transition at $\sim 0.56 \mathrm{~cm}^{-1}$ (Figure S18) further supporting our exchange model.

The expected dipolar interaction between the two $\operatorname{Er}(\mathrm{III})$ ions within $\mathrm{Er}_{2}$ can be calculated using the experimentally obtained $g$ values and fitted orientations (Equation S2). The resultant exchange matrix (expressed in the diagonal reference frame of the fitted total exchange, Equation 5) shows largest values for $J_{\mathrm{xy}}$ and $J_{\mathrm{yy}}$, which are of similar magnitude to the exchange parameters determined in our fitting. Therefore, the dipolar mechanism must be a significant component to the overall interaction; this is a similar result to that found for $\mathrm{Dy}_{2} \cdot{ }^{18}$ The experimental exchange matrix is diagonal in this reference frame and has $J_{\mathrm{zz}}$ as the major component; the significant difference between these two matrices suggests that dipolar interactions alone are not sufficient to describe the interaction and therefore that superexchange is also important. While simulation of the EPR spectra using only dipolar exchange shows reasonable agreement with the experimental data (Figure S19) these simulations are unable to reproduce all experimental features.

$$
\begin{aligned}
& \overline{\bar{R}}^{T} \cdot \overline{\bar{J}}_{E r_{2}}^{d i p} \cdot \overline{\bar{R}}=\left(\begin{array}{ccc}
-0.159 & 0.108 & 0.011 \\
0.376 & 0.269 & 0.186 \\
0.098 & 0.130 & 0.047
\end{array}\right) \\
& \overline{\bar{R}}^{T} \cdot \overline{\bar{J}}_{E r_{2}} \cdot \overline{\bar{R}}=\left(\begin{array}{ccc}
-0.057 & 0 & 0 \\
0 & 0.45 & 0 \\
0 & 0 & 0.72
\end{array}\right)
\end{aligned}
$$

The zero-field exchange manifold for $\mathrm{Yb}_{2}$ consists of one doublet and two singlets spanning $0.54 \mathrm{~cm}^{-1}$ (Table S11). The second to third excited state pair has the largest magnetic moment transition probability, with the transition energy in good agreement with the low energy shoulder in the INS data (Figure S35). The calculated dipolar interaction matrix for $\mathrm{Yb}_{2}$ contains elements of $\leq 0.091 \mathrm{~cm}^{-1}$ magnitude (in the diagonal reference frame of the fitted total exchange, Equation 7), which are of much smaller magnitude than those for $\mathrm{Er}_{2}$ because of the lower magnetic moment of $\mathrm{Yb}(\mathrm{III})$. Clearly the dipolar interaction is significantly weaker than the total fitted exchange (Equation 8). It is therefore unsurprising that dipolar interactions alone reproduce the 
experimental EPR spectra very poorly (Figure S36). Therefore, there must be a significant superexchange interaction for $\mathrm{Yb}_{2}$.

$$
\begin{aligned}
& \overline{\bar{R}}^{T} \cdot \overline{\bar{J}}_{Y b_{2}}^{d i p} \cdot \overline{\bar{R}}=\left(\begin{array}{ccc}
-0.034 & 0.014 & -0.011 \\
0.034 & -0.091 & 0.061 \\
0.007 & -0.014 & 0.019
\end{array}\right) \\
& \overline{\bar{R}}^{T} \cdot \overline{\bar{J}}_{Y b_{2}} \cdot \overline{\bar{R}}=\left(\begin{array}{ccc}
-0.25 & 0 & 0 \\
0 & 0.25 & 0 \\
0 & 0 & -0.29
\end{array}\right)
\end{aligned}
$$

Further evidence of a real superexchange component in the $\mathrm{Ln}_{2}$ dimetallic species comes from the almost identical value for $\gamma_{e x}$ of $8.85^{\circ}$ and $8.50^{\circ}$ for $\mathrm{Er}_{2}$ and $\mathrm{Yb}_{2}$, respectively, which have been independently determined. With $J_{\mathrm{zz}}$ defined along the internuclear Ln-Ln vector, this value of $\gamma_{e x}$ places the orientation of $J_{\text {yy }}$ towards the longest $\mathrm{Ln}_{\mathrm{hq}}-\mathrm{O}$ bond bridging the two Ln centers (2.373(7) and 2.344(2) $\AA$ for $\mathrm{Er}_{2}$ and $\mathrm{Yb}_{2}$, respectively (Table S12, Figures S39 and S40). The presence of a structural feature coincident with one of the principal directions of the anisotropic exchange matrix reinforces the proposal of a through-bond superexchange component. Examination of the structural data for the diamagnetic Y(III) and Lu(III) analogs (Table S12), shows that these species also exhibit the same characteristically long $\mathrm{Ln}_{\mathrm{hq}}-\mathrm{O}$ bond; this is an indication that the origin of the elongation is not magnetic in nature, but rather that this structural feature dictates part of the magnetic superexchange. Identification of this link between the molecular structure and the exchange interaction in these dimetallic $\mathrm{Ln}_{2}$ compounds, along with the experimentally determined exchange states, is a further step towards the establishment of an overarching microscopic model for the magnetic exchange in Ln complexes.

\section{Conclusion}

We have been able to measure directly and model the magnetic interactions between highly anisotropic lanthanide ions in asymmetric dimetallic compounds. Through the exploitation of size selectivity, dilution experiments enabled experimental determination of the magnetic properties for each individual site using EPR spectroscopy. INS and FIR measurements were employed to support CASSCF-SO calculations for identifying the origin of the magnetic signals for each site in the molecule. By fixing the principal $g$-values from experiment, simulations of multi-frequency EPR spectra of the pure species provide direct measurement of the exchange interactions. Our models are also in good agreement with low temperature magnetometry and INS data. Our results show that dipolar interactions are a significant component of, but not solely responsible for, the magnetic interactions in $\mathrm{Er}_{2}$ (as previously found for $\mathrm{Dy}_{2}{ }^{18}$ ), while for $\mathrm{Yb}_{2}$ the superexchange interactions are important and the dipolar exchange is peripheral. Moreover, we find a link between the geometry of an Ln-O-Ln bridge and the magnetic exchange interactions in both $\mathrm{Er}_{2}$ and $\mathrm{Yb}_{2}$ molecules, providing an additional piece of data to guide the development of theoretical models of magnetic exchange. It is our hope that subsequent theoretical studies of these systems will yield microscopic information regarding the origin of the superexchange interaction, and potentially shed light on the feasibility of tailoring superexchange interactions by chemical design.

\section{Experimental}

Synthesis. Samples were prepared through modification of the synthetic procedure reported in reference $18.440 \mathrm{mg}(3.0 \mathrm{mmol})$ of 8-hydroxyquinoline was added to $40 \mathrm{~mL}$ methanol containing $437-561 \mathrm{mg}$ (1.2 mmol) of $\mathrm{LnNO}_{3} \cdot \mathrm{xH}_{2} \mathrm{O}$ and heated to reflux for
4 hours. The solution was hot filtered and left to crystallize by slow evaporation to yield yellow crystals suitable for single crystal X-ray diffraction (XRD). Dilute samples were prepared using the same procedure employing a 1:19 (5\%) mole ratio of $\mathrm{Ln}: \mathrm{Lu}$ or $\mathrm{Ln}: \mathrm{Y}$. Samples were characterized by $\mathrm{CHN}$ microanalysis and powder XRD (PXRD) measurements to establish phase purity of the bulk sample.

Magnetic measurements. Magnetometry was performed in the temperature range 1.8 to $300 \mathrm{~K}$ with a Quantum Design MPMSXL7 SQUID magnetometer equipped with a $7 \mathrm{~T}$ magnet. Lightly ground crystalline samples were placed in a gel capsule and restrained with a small amount of eicosane to avoid alignment during measurements. Diamagnetic corrections based on calibrated blanks were applied to the data to account for the gel capsule and eicosane, while Pascal's constants were used for the diamagnetic contribution of the complex.

Electron paramagnetic resonance. EPR spectra were collected at X- and Q-band with a Bruker EMX300 spectrometer and at Sband with a Bruker Elexsys580 spectrometer. Data were collected on lightly ground polycrystalline samples with the use of eicosane in some cases to avoid magnetic torque during measurements. High field EPR (HF-EPR) spectra $(260-380 \mathrm{GHz})$ were recorded at the University of Stuttgart on a home-built spectrometer. The radiation source is a $0-20 \mathrm{GHz}$ signal generator (Anritsu) in combination with an amplifier-multiplier chain (VDI) to obtain the required frequencies. It features a quasi-optical bridge (Thomas Keating) and induction mode detection. The detector is a QMC magnetically tuned InSb hot electron bolometer. The sample is located in an Oxford Instruments 15/17T cryomagnet equipped with a variable temperature insert $(1.5-300 \mathrm{~K})$.

Inelastic neutron scattering. INS spectra were collected at the ISIS neutron source facility on the LET, IRIS and MARI spectrometers. Powder samples of $\sim 2 \mathrm{~g}$ were prepared for each analogue and lightly ground. The samples were loaded in annular $\mathrm{Al}$ cans for IRIS, while for MARI and LET they were placed in an $\mathrm{Al}$ foil pocket and then inserted into an $\mathrm{Al}$ cylindrical can for measurements. The samples were cooled to $2 \mathrm{~K}$ (IRIS) and $5 \mathrm{~K}$ (LET and MARI), using a cryostat and closed cycle refrigerator, respectively. The data were then integrated over the appropriate low $\mathrm{Q}$ range, $0<|\mathrm{Q}|<2 \AA$ (LET), $0<|\mathrm{Q}|<2 \AA$ (IRIS), $0<|\mathrm{Q}|<$ $3 \AA$ (MARI $E_{\mathrm{i}} 15$ and $25 \mathrm{meV}$ ), and $0<|\mathrm{Q}|<4 \AA, 0<|\mathrm{Q}|<5 \AA$ (MARI $E_{\mathrm{i}} 50$ and $100 \mathrm{meV}$, respectively). Broad phonon peaks in the $\mathrm{Lu}_{2}$ analog are observed at ca. $5\left(40 \mathrm{~cm}^{-1}\right), 9\left(73 \mathrm{~cm}^{-1}\right), 12(97$ $\left.\mathrm{cm}^{-1}\right)$ and $19 \mathrm{meV}\left(153 \mathrm{~cm}^{-1}\right)$ with weaker features also present at around $16\left(139 \mathrm{~cm}^{-1}\right), 36\left(290 \mathrm{~cm}^{-1}\right)$ and $38 \mathrm{meV}\left(307 \mathrm{~cm}^{-1}\right)$. The MARI elastic resolutions for incident energies of $15,25,50$ and $100 \mathrm{meV}$ are $0.65,0.95,2.75$ and $5.79 \mathrm{meV}$, respectively. IRIS measurements were performed using the pyrolytic (002) graphite analyzers which give a final energy of $1.845 \mathrm{meV}$ and an energy resolution of $18 \mu \mathrm{eV}$ (FWHM). The LET measurements were performed with an incident energy of 1.0 and $2.5 \mathrm{meV}$ (20 and 70 $\mu \mathrm{eV}$ energy resolution at the elastic line respectively). The 15 and $25 \mathrm{meV}$ data for $\mathrm{Er}_{2}$ following phonon subtraction were used to fit peak locations with errors reported in brackets throughout manuscript.

Ab initio calculations. CASSCF-SO calculations were performed with MOLCAS $8.0^{46}$ using the geometry of the isolated metal complex as previously reported from XRD. ${ }^{18}$ The calculations considered each site in the dimetallic compounds independently, where the ion not in focus was replaced by a diamagnetic Y(III) ( $\mathrm{Y}_{2}$ structure $)$ or $\mathrm{Lu}(\mathrm{III})$ ion $\left(\mathrm{Er}_{2}, \mathrm{Yb}_{2}\right.$ and $\mathrm{Lu}_{2}$ structures). Basis 
sets from the MOLCAS ANO-RCC library ${ }^{47,48}$ were employed with the paramagnetic ion described using VTZP quality, the first coordination sphere with VDZP quality, and all other atoms with $\mathrm{VDZ}$ quality. The active space in all cases for $\mathrm{Er}(\mathrm{III})$ and $\mathrm{Yb}(\mathrm{III})$ were 11 and 13 active electrons in seven $4 \mathrm{f}$ orbitals, respectively. The CASSCF calculations were performed on 35 and 112 states for the quartet and doublet spin states of Er, respectively, with all states incorporated for SO coupling. For $\mathrm{Yb}$, the 7 doublet states were employed for both CASSCF and SO coupling calculations. Further calculations for $\mathrm{Er}_{2}$ were performed with the inclusion of the two nearest $\mathrm{hqH}_{2}^{+}$cations followed by additional point charges describing a $25 \AA$ radius from the $\mathrm{NO}_{3}$ pocket, including only atoms carrying formal charges $\left(\mathrm{NO}_{3}\right.$ molecules with +1 on $\mathrm{N}$ and $-2 / 3$ on $\mathrm{O},+3$ for $\operatorname{Er}(\mathrm{III})$ ions, -1 for deprotonated $\mathrm{O}^{-}$on the hq ligands and +1 for protonated $\mathrm{N}^{+}$on the hq cation).

Far infrared. FIR spectra were recorded using a Bruker $113 \mathrm{v}$ FTIR spectrometer equipped with a mercury light source and Infrared Laboratories pumped $\mathrm{Si}$ bolometer (operating temperature $1.5 \mathrm{~K}$ ) detector. Samples consisted of $10 \mathrm{~mm}$ pressed powder pellets, and were contained in an Oxford Instruments Spectromag 4000 optical cryostat allowing fields up to $8 \mathrm{~T}$ and temperatures down to $1.8 \mathrm{~K}$. The spectra presented are normalized to the $6 \mathrm{~T}$ data, where peaks that show significant field dependence are assigned as magnetic in origin.

\section{ASSOCIATED CONTENT}

The supporting information is available free of charge via the Internet at http://pubs.acs.org.

Structural, magnetometry, EPR, INS, FIR and CASSCF-SO data for $\mathrm{Er}_{2}$ and $\mathrm{Yb}_{2}$, investigations of the INS scaling factor for $\mathrm{Er}_{2}$, modelling magnetic exchange for $\mathrm{Er}_{2}$ and $\mathrm{Yb}_{2}$, interpretation of the exchange model, connection between $J, m_{J}$ states and effective $S=1 / 2 g$-values.

\section{AUTHOR INFORMATION}

\section{Corresponding Author}

*nicholas.chilton@manchester.ac.uk

\section{Present Addresses}

$\dagger$ Eufemio Moreno-Pineda now at Karlsruhe Institute of Technology, Karlsruhe, Germany

\section{Funding Sources}

The University of Manchester, The Ramsay Memorial Trust (fellowship to NFC), EPSRC, MIUR, DFG (SL104/5-1).

\section{ACKNOWLEDGMENT}

We acknowledge funding from the EPSRC and access to The EPSRC National EPR Facility in the Photon Science Institute at The University of Manchester. N.F.C. thanks the Ramsay Memorial Trust for a Research Fellowship. M.J.G. thanks The University of Manchester for a President's Doctoral Scholarship. R.H. thanks The Italian Ministry of Education, Universities and Research (MIUR) for a Doctoral Scholarship. This work was supported within the CNR-STFC agreement 2014-2020 (No. 3420 2014-2020) concerning collaboration in scientific research at ISIS Spallation Neutron Source. R.H. and S.C. acknowledge financial support from PRIN Project 2015 No. HYFSRT of the MIUR (Italy).

\section{REFERENCES}

(1) Aguilà, D.; Barrios, L. A.; Velasco, V.; Roubeau, O.;
Repollés, A.; Alonso, P. J.; Sesé, J.; Teat, S. J.; Luis, F.; Aromi, G.; Pablo, J. J. Am. Chem. Soc. 2014, 136, 14215.

(2) Pedersen, K. S.; Ariciu, A.-M.; McAdams, S. G.; Weihe, H.; Bendix, J.; Tuna, F.; Piligkos, S. J. Am. Chem. Soc. 2016, 138, 5801.

(3) Shiddiq, M.; Komijani, D.; Duan, Y.; Gaita-Ariño, A.; Coronado, E.; Hill, S. Nature 2016, 531, 348.

(4) Gregson, M.; Chilton, N. F.; Ariciu, A.-M.; Tuna, F.; Crowe, I. F.; Lewis, W.; Blake, A. J.; Collison, D.; McInnes, E. J. L.; Winpenny, R. E. P.; Liddle, S. T. Chem. Sci. 2016, 7, 155.

(5) Liu, J.; Chen, Y. C.; Liu, J. L.; Vieru, V.; Ungur, L.; Jia, J. H.; Chibotaru, L. F.; Lan, Y.; Wernsdorfer, W.; Gao, S.; Chen, X. M.; Tong, M. L. J. Am. Chem. Soc. 2016, 138, 5441.

(6) Ding, Y. S.; Chilton, N. F.; Winpenny, R. E. P.; Zheng, Y. Z. Angew. Chemie - Int. Ed. 2016, 55, 16071.

(7) Harriman, K. L. M.; Brosmer, J. L.; Ungur, L.; Diaconescu, P. L.; Murugesu, M. J. Am. Chem. Soc. 2017, 139, 1420.

(8) McAdams, S. G.; Ariciu, A.-M.; Kostopoulos, A. K.; Walsh, J. P. S.; Tuna, F. Coord. Chem. Rev. 2017, 346, 216.

(9) Goodwin, C. A. P.; Ortu, F.; Reta, D.; Chilton, N. F.; Mills, D. P. Nature 2017, 548, 439.

(10) Wernsdorfer, W.; Aliaga-Alcalde, N.; Hendrickson, D. N.; Christou, G. Nature 2002, 416, 406.

(11) Moreno-Pineda, E.; Lan, Y.; Fuhr, O.; Wernsdorfer, W.; Ruben, M. Chem. Sci. 2017, 8, 1178.

(12) Rinehart, J. D.; Fang, M.; Evans, W. J.; Long, J. R. J. Am. Chem. Soc. 2011, 133, 14236.

(13) Meihaus, K. R.; Corbey, J. F.; Fang, M.; Ziller, J. W.; Long, J. R.; Evans, W. J. Inorg. Chem. 2014, 53, 3099.

(14) Rinehart, J. D.; Fang, M.; Evans, W. J.; Long, J. R. Nat. Chem. 2011, 3, 538.

(15) Iwahara, N.; Chibotaru, L. F. Phys. Rev. B - Condens. Matter Mater. Phys. 2015, 91, 174438.

(16) Lukens, W. W.; Magnani, N.; Booth, C. H. Inorg. Chem. 2012, 51, 10105.

(17) Palii, A.; Tsukerblat, B.; Clemente-Juan, J. M.; Coronado, E. Int. Rev. Phys. Chem. 2010, 29, 135.

(18) Moreno-Pineda, E.; Chilton, N. F.; Marx, R.; Dörfel, M.; Sells, D. O.; Neugebauer, P.; Jiang, S.-D.; Collison, D.; van Slageren, J.; McInnes, E. J. L.; Winpenny, R. E. P. Nat. Commun. 2014, $5,5243$.

(19) Kofu, M.; Yamamuro, O.; Kajiwara, T.; Yoshimura, Y.; Nakano, M.; Nakajima, K.; Ohira-Kawamura, S.; Kikuchi, T.; Inamura, Y. Phys. Rev. B 2013, 88, 64405.

(20) Marx, R.; Moro, F.; Dörfel, M.; Ungur, L.; Waters, M.; Jiang, S. D.; Orlita, M.; Taylor, J.; Frey, W.; Chibotaru, L. F.; van Slageren, J. Chem. Sci. 2014, 5, 3287.

(21) Baker, M. L.; Tanaka, T.; Murakami, R.; Ohira-Kawamura, S.; Nakajima, K.; Ishida, T.; Nojiri, H. Inorg. Chem. 2015, 54, 5732 .

(22) Vonci, M.; Giansiracusa, M. J.; Gable, R. W.; Van den Heuvel, W.; Latham, K.; Moubaraki, B.; Murray, K. S.; Yu, D.; Mole, R. A.; Soncini, A.; Boskovic, C. Chem. Commun. 2016, 52, 2091.

(23) Giansiracusa, M. J.; Vonci, M.; Van Den Heuvel, W.; Gable, R. W.; Moubaraki, B.; Murray, K. S.; Yu, D.; Mole, R. A.; Soncini, A.; Boskovic, C. Inorg. Chem. 2016, 55, 5201.

(24) Vonci, M.; Giansiracusa, M. J.; Van Den Heuvel, W.; Gable, R. W.; Moubaraki, B.; Murray, K. S.; Yu, D.; Mole, R. A.; Soncini, A.; Boskovic, C. Inorg. Chem. 2017, 56, 378.

(25) Furrer, A.; Güdel, H. U.; Blank, H.; Heidemann, A. Phys. Rev. Lett 1989, 62, 210.

(26) Güdel, H. U.; Furrer, A.; Blankic, H. Inorg. Chem. 1990, 29, 4081.

(27) Donni, A.; Furrer, A.; Blank, H.; Heidemann, A. Phys. B 
1989, 157, 370.

(28) Glerup, J.; Weihe, H. Inorg. Chem. 1997, 36, 2816.

(29) Aebersold, M. A.; Güdel, H. U.; Furrer, A.; Blanks, H. Inorg. Chem. 1994, 33, 1113.

(30) Furrer, A.; Güdel, H.; Krausz, E.; Blank, H. Phys. Rev. Lett. 1990, 64, 68 .

(31) Boeer, A. B.; Barra, A.-L.; Chibotaru, L. F.; Collison, D.; McInnes, E. J. L.; Mole, R. A.; Simeoni, G. G.; Timco, G. A.; Ungur, L.; Unruh, T.; Winpenny, R. E. P. Angew. Chemie Int. Ed. 2011, 50, 4007.

(32) Bencini, A.; Gatteschi, D. EPR of Exchange Coupled Systems, 1st ed.; Springer-Verlag: Berlin, 2012.

(33) Neuman, N. I.; Winkler, E.; Peña, O.; Passeggi, M. C. G.; Rizzi, A. C.; Brondino, C. D. Inorg. Chem. 2014, 53, 2535.

(34) Dreiser, J.; Pedersen, K. S.; Schnegg, A.; Holldack, K.; Nehrkorn, J.; Sigrist, M.; Tregenna-Piggott, P.; Mutka, H.; Weihe, H.; Mironov, V. S.; Bendix, J.; Waldmann, O. Chem. - A Eur. J. 2013, 19, 3693.

(35) Bertini, I.; Luchinat, C.; Parigi, G.; Ravera, E. NMR of Paramagnetic Molecules, 2nd ed.; Elsevier: Amsterdam, Oxford, Cambridge, 2017.

(36) Garlatti, E.; Bordignon, S.; Carretta, S.; Allodi, G.; Amoretti, G.; De Renzi, R.; Lascialfari, A.; Furukawa, Y.; Timco, G. A.; Woolfson, R.; Winpenny, R. E. P.; Santini, P. Phys. Rev. B 2016, 93, 1.

(37) Bordonali, L.; Furukawa, Y.; Mariani, M.; Sabareesh, K. P. V; Garlatti, E.; Carretta, S.; Lascialfari, A.; Timco, G.; Winpenny, R. E. P.; Borsa, F. J. Appl. Phys. 2014, 115, 7.

(38) Adelnia, F.; Chiesa, A.; Bordignon, S.; Carretta, S.; Ghirri, A.; Candini, A.; Cervetti, C.; Evangelisti, M.; Affronte, M.; Sheikin, I.; Winpenny, R.; Timco, G.; Borsa, F.; Lascialfari, A. J. Chem. Phys. 2015, 143, 244321.

(39) Chilton, N. F.; Anderson, R. P.; Turner, L. D.; Soncini, A.; Murray, K. S. J. Comput. Chem. 2013, 34, 1164.

(40) Stoll, S.; Schweiger, A. J. Magn. Reson. 2006, 178, 42.

(41) Shannon, R. D. Acta Crystallogr. Sect. A 1976, 32, 751.

(42) Templeton, D. H.; Dauben, C. H. J. Am. Chem. Soc. 1954, $76,5237$.

(43) Rudowicz, C. J. Phys. C Solid State Phys. 1985, 18, 1415.

(44) Arnold, O.; Bilheux, J. C.; Borreguero, J. M.; Buts, A.; Campbell, S. I.; Chapon, L.; Doucet, M.; Draper, N.; Ferraz Leal, R.; Gigg, M. A.; Lynch, V. E.; Markvardsen, A.; Mikkelson, D. J.; Mikkelson, R. L.; Miller, R.; Palmen, K.; Parker, P.; Passos, G.; Perring, T. G.; Peterson, P. F.; Ren, S.; Reuter, M. A.; Savici, A. T.; Taylor, J. W.; Taylor, R. J.; Tolchenov, R.; Zhou, W.; Zikovsky, J. Nucl. Instruments Methods Phys. Res. Sect. A Accel. Spectrometers, Detect. Assoc. Equip. 2014, 764, 156.

(45) Denning, R. G.; Harmer, J.; Green, J. C.; Irwin, M. J. Am. Chem. Soc. 2011, 133, 20644.

(46) Aquilante, F.; Autschbach, J.; Carlson, R. K.; Chibotaru, L. F.; Delcey, M. G.; De Vico, L.; Fdez. Galván, I.; Ferré, N.; Frutos, L. M.; Gagliardi, L.; Garavelli, M.; Giussani, A.; Hoyer, C. E.; Li Manni, G.; Lischka, H.; Ma, D.; Malmqvist, P. Å.; Müller, T.; Nenov, A.; Olivucci, M.; Pedersen, T. B.; Peng, D.; Plasser, F.; Pritchard, B.; Reiher, M.; Rivalta, I.; Schapiro, I.; Segarra-Martí, J.; Stenrup, M.; Truhlar, D. G.; Ungur, L.; Valentini, A.; Vancoillie, S.; Veryazov, V.; Vysotskiy, V. P.; Weingart, O.; Zapata, F.; Lindh, R. J. Comput. Chem. 2016, 37, 506.

(47) Roos, B. O.; Lindh, R.; Malmqvist, P.-Å.; Veryazov, V.; Widmark, P.-O. J. Phys. Chem. A 2008, 112, 11431.

(48) Roos, B. O.; Lindh, R.; Malmqvist, P. Å.; Veryazov, V.; Widmark, P. O. J. Phys. Chem. A 2004, 108, 2851. 
Insert Table of Contents artwork here

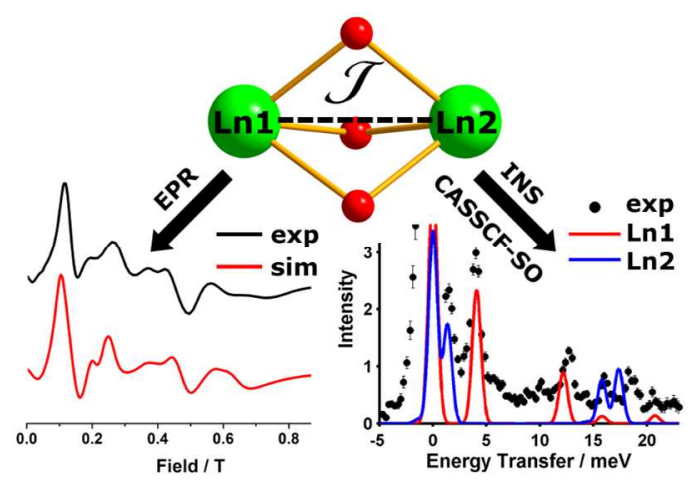

